\title{
Comunidade que sustenta a agricultura (CSA): representa uma tendência de transição do sistema agroalimentar?
}

\begin{abstract}
Marina de Camargo Santos Neta ${ }^{1}$
Glauco Schultz ${ }^{2}$

Marcelino de Souza ${ }^{3}$

Submissão: 30/09/2021

Aceite: $22 / 10 / 2021$

Resumo

A partir das discussões nos círculos acadêmicos, políticos e econômicos sobre o sistema produtivo existente nas últimas décadas, questiona-se a transição do sistema agroalimentar, pensando-se, nesse contexto, a comunidade que sustenta a agricultura (CSA), se esta poderia representar uma tendência dessa mudança. No sentido de ser um movimento internacional, que busca implementar uma rede comunitária alimentar periurbana, promovendo o fortalecimento da agricultura familiar por meio do financiamento prévio da produção, gerando uma estabilidade financeira ao agricultor. Por conseguinte, este artigo visa observar a CSA, de modo a descrever as características de produção, distribuição e desenvolvimento dessa comunidade no Distrito Federal. Nos resultados, pode-se observar que a transição do regime agroalimentar ocorre de forma regular, com surgimento de alguns movimentos que buscam minimizar os impactos ambientais, até mesmo com a grande indústria tendo que se adaptar aos protocolos internacionais, com condicionalidades. Ao mesmo tempo, com a população mais urbanizada, necessita-se de um mercado próximo para abastecer essa demanda, com consumidores mais ativos e preocupados com questões além da sua dieta. Logo, as CSAs acabam por atingir pequenos nichos que não têm o peso econômico ou o poder de produzir a transformação necessária do sistema agroalimentar, mas têm a possibilidade de se apresentar como um gérmen de uma mudança, ao propor um novo modelo de articulação entre produtores e consumidores, bem como disseminar e aumentar a influência sobre outros agentes para adotar tal modelo.
\end{abstract}

Palavras-chave: comunidade que sustenta a agricultura; regime alimentar; transição agroalimentar.

\section{Community supported agriculture (CSA): does it represent a transition trend of the agri-food system?}

\begin{abstract}
Based on discussions in academic, political and economic circles about the productive system that has existed in recent decades, the transition from the agri-food system is questioned, considering in this context, the community supported agriculture (CSA), if this could represent a trend of this change In the sense that it is an international movement, which seeks to implement a peri-urban community food network, promoting the strengthening of family farming through the pre-financing of production, generating financial stability for the farmer. Therefore, this article aims to observe the Community Supports Agriculture (CSA), in order to describe the characteristics of production, distribution and development of this Community in the Federal District. In the results, it can be observed that the transition from the agri-food regime occurs on a regular basis, with the appearance of some movements that seek to minimize environmental impacts, even the large industry, having to adapt to international protocols, with conditionalities. At the same time, with the more urbanized population, a close market is needed to supply this demand, with consumers more active and concerned with issues beyond their diet. Therefore, the CSAs end up reaching small niches that do not have the economic weight or the power to produce the necessary transformation
\end{abstract}

\footnotetext{
${ }^{1}$ Mestranda do Programa de Pós-Graduação em Agronegócios da Universidade Federal do Rio Grande do Sul (UFRGS). Orcid iD: 0000-0002-2352-4312. Email:marinaneta98@gmail.com

2 Doutorado em Agronegócios (UFRGS). Professor dos Programas de Pós-Graduação em Desenvolvimento Rural e em Agronegócios da Universidade Federal do Rio Grande do Sul (UFRGS). Orcid iD:0000-0002-7569-7434. Email:glauco.schultz@ufrgs.br

${ }^{3}$ Doutorado em Engenharia Agrícola (UNICAMP). Professor dos Programas de Pós-Graduação em Desenvolvimento Rural e em Agronegócios da Universidade Federal do Rio Grande do Sul (UFRGS). Orcid iD: 0000-0001-6044-6694.

Email:marcelino.souza@uol.com.br
} 
of the agri-food system but have the possibility of presenting themselves as a seed of change by proposing a new model of articulation between producers and consumers, as well as to disseminate and increase influence over other agents to adopt this model.

Keywords: community supported agriculture; food regime; agri-food transition.

\section{Introdução}

Existem atualmente discussões nos meios acadêmico, político e econômico a respeito do sistema produtivo existente nas últimas décadas, que ultimamente tende a uma transição dos processos desenvolvidos até então, aprimorados conforme a demanda do mercado. Além da mudança no comportamento e na visão do consumidor, que busca um maior entendimento do que é consumido, agregando um valor acima do nutricional, também se observa uma transição na visão dos órgãos governamentais.

Um exemplo nesse sentido são as três metas do Objetivo de Desenvolvimento Sustentável (ODS 2): "Fome Zero e Agricultura Sustentável", que trata dos mercados agroalimentares e de seu funcionamento, em que se destacam no quadro da Agenda 2030 para o Desenvolvimento Sustentável da Organização das Nações Unidas (ONU). A Meta 2.1 visa acabar com a fome por meio de alimentos seguros, nutritivos e suficientes durante o ano inteiro, evidenciando a importância da segurança alimentar e da sazonalidade dos alimentos ao longo dos ciclos produtivos. A Meta 2.3 visa a produtividade agrícola e a renda dos pequenos agricultores familiares, proporcionando acesso a: terra, recursos produtivos, insumos necessários e oportunidades de agregação de valor. Por fim, a Meta 2.4 aborda a garantia do funcionamento adequado dos mercados de alimentos e seus derivados, a fim de auxiliar na volatilidade extrema dos preços dos alimentos (UNITED NATIONS, 2015).

Os ODS adotados pelos Estados-Membros das Nações Unidas em setembro de 2015 mostram que a transição para a sustentabilidade dos atuais sistemas agrícolas e alimentares, incluindo os mercados agroalimentares, é uma tendência para os próximos anos, com o intuito de alcançar a segurança alimentar e nutricional sustentável (BORSELLINO; SCHIMMENTI; EL BILALI, 2020). Desse modo, observa-se a confluência de diferentes agentes globais e domésticos, levando a algumas mudanças graduais no funcionamento e na estrutura dos mercados agroalimentares em todo o mundo. Isso inclui a globalização, a liberalização do comércio, o crescimento populacional, a urbanização, o aumento da renda, a mudança de políticas e dos padrões de consumo de alimentos e dietas, as mudanças tecnológicas e a degradação ambiental (BORSELLINO; SCHIMMENTI; EL BILALI, 2020). 
O International Fund for Agricultural Development (IFAD) sugere, no Relatório de Desenvolvimento Rural (2016), que as mudanças nas políticas e nos padrões alimentares foram os principais motores da transformação dos mercados agroalimentares nas últimas décadas. As mudanças na política estão relacionadas aos processos de privatização e liberalização, que diminuíram o controle dos Estados sobre os mercados agroalimentares, bem como os investimentos públicos em estruturas de mercado e infraestrutura. Nesse ínterim, a crescente urbanização, a inserção da mulher no mercado de trabalho, o surgimento de padrões de consumo modernos, as novas tendências no comércio internacional e os aumentos de renda da população em geral modificaram a demanda de alimentos dos consumidores e induziram o surgimento de mudanças dietéticas, especialmente em países emergentes e em países em desenvolvimento.

A transformação contínua dos mercados agroalimentares significa tanto desafios quanto oportunidades para os produtores e atores das cadeias, em níveis global, doméstico e local. De fato, o funcionamento dos mercados agroalimentares afeta a segurança alimentar, já que são eles que ditam as normativas para o pleno funcionamento. Portanto, alcançar a segurança alimentar e nutricional em longo prazo significa compreender a dinâmica do comércio agroalimentar global, assim como a governança e o funcionamento dos mercados agroalimentares domésticos (BORSELLINO; SCHIMMENTI; EL BILALI, 2020).

Com o intuito de abranger essa transição do processo produtivo, observa-se a rede alimentar denominada comunidade que sustenta a agricultura (CSA), com a premissa de resgatar a valorização do homem do campo e reaproximar os consumidores da realidade em que os agricultores vivem no dia a dia. Essa rede de comercialização define que o pequeno produtor familiar, o agricultor, comercialize um produto orgânico, de forma sustentável e respeitando a sazonalidade das safras e, em conjunto com o seu trabalho, o consumidor, que se insere na cadeia como coagricultor, um participante monetário, que faz o financiamento das cestas de alimentos que são abastecidas conforme a oferta nas propriedades, promovendo a revalorização das culturas alimentares e territoriais, estimulando o comércio justo, promovendo a defesa e a proteção do bem comum, especialmente no que tange à sustentabilidade econômica e social, como também ao meio ambiente (JUNQUEIRA; MORETTI, 2018).

A partir da definição de Pascucci (2010) como uma "rede comunitária alimentar", que se encaixa como uma nova estrutura de governança, tem-se o questionamento: essa rede comunitária alimentar é uma resposta da tendência do sistema agroalimentar? No sentido de ser um movimento de âmbito mundial, que representa uma perspectiva da transição do sistema 
agroalimentar no mundo inteiro, marcado não só pela CSA, mas também por estruturas similares, ao mencionar a transição de um sistema, refere-se à ocorrência de uma mudança em grande escala, a qual implica no envolvimento de diferentes agentes, que possuem objetivos que tendem ao desacordo.

A noção de "sistema agroalimentar" refere-se a um conjunto de atores e instituições, tecnologias e processos envolvidos na produção, na circulação e no consumo agroalimentar de uma economia, abrangendo os distintos elos e nós das suas cadeias e redes de mercadorias, desde o produtor primário até o consumidor final (SCHNEIDER; SCHUBERT; ESCHER, 2016). IsSo passa por indústrias de insumos e máquinas, transporte, agroindústria processadora, comércio atacadista e varejista, mercados locais, domésticos e externos, Estados e suas políticas públicas e inter-relações entre esses diversos componentes.

Pensando no sistema agroalimentar e como ele é altamente globalizado, o que o tornou uma cadeia mais longa de escala mundial, com expressiva quantidade de informações, muitos agentes envolvidos na produção e comercialização, é possível perceber que, nas últimas décadas, os fluxos e a circulação de alimentos, fibras e matérias-primas ampliaram-se de forma exponencial, transformando o setor agroalimentar em uma indústria de grande interesse e fonte de riqueza (SCHNEIDER; SCHUBERT; ESCHER, 2016). Porém, não menos importantes e expressivos são os problemas que surgiram a partir desse processo, podendo-se citar, como exemplos, a homogeneização das dietas alimentares, largamente baseadas na combinação de carboidratos e proteínas de origem animal, e os impactos ambientais generalizados (SCHNEIDER; SCHUBERT; ESCHER, 2016).

Logo, percebemos que existe uma relação de ganhos-perdas, gerando riquezas associadas a processos degenerativos, ou seja, alta produtividade, desenvolvimento de tecnologia de ponta, uma produção capaz de produzir diversas categorias de alimentos, quando a matéria-prima passa por um processamento industrial, escala global de produção e processamento dos alimentos. Contudo, todo esse desenvolvimento tem sido marcado também por situações que necessitam de atenção devido à exploração desenfreada por esse regime alimentar, que usufrui de recursos finitos (água, terra, etc.) de forma expansiva e não gera um contraponto de preservá-los, pensando-se no longo prazo da sociedade.

Então, os debates acerca desse regime alimentar procuram sanar as dúvidas desses impactos e, principalmente, encontrar formas mais sustentáveis de produção. Assim, para esclarecer a questão do que é regime alimentar, Schneider, Schubert e Escher (2016, p. 34) definem: 
Regime alimentar permite apreender a existência de uma lógica política e econômica global na dinâmica da agricultura e da alimentação na evolução do capitalismo. Esse processo se expressa por meio das estratégias, ações, políticas e práticas desenvolvidas por certos atores (grandes empresários, investidores, proprietários fundiários, agricultores) e instituições econômicas e políticas (corporações transnacionais, bancos, burocracias estatais, grupos de interesse, agências multilaterais, movimentos sociais). Disso resulta uma determinada configuração que enseja conflitos de poder e hegemonia que se refletem historicamente nas formas institucionais através das quais as relações de produção, troca, distribuição e consumo de mercadorias agropecuárias e alimentares são ordenadas e os sistemas agroalimentares nacionais se inter-relacionam em escala global, dando origem ao que os autores chamam "regimes alimentares internacionais".

Assim sendo, busca-se observar a CSA por meio da apresentação e da análise da Rede CSA Brasília, exibindo aspectos dessa estrutura e como esta se comporta, tentando evidenciar a ocorrência de um processo de transição agroalimentar e se esta rede é uma representação disso.

Para efeito de apresentação e sistematização, o artigo está estruturado em quatro seções: a primeira é a introdução; na segunda, apresenta-se a metodologia utilizada na pesquisa; na terceira, encontram-se os resultados e a discussão. A quarta e última seção contém as considerações finais.

\section{Metodologia}

Para alcançar o objetivo deste estudo, optou-se pela realização de uma pesquisa exploratória. Segundo Selltiz, Wrightsman e Cook (1965), os estudos exploratórios almejam inferir ideias e intuições, adquirindo, de tal modo, maior familiaridade com o fenômeno pesquisado. O planejamento da pesquisa deve ser flexível e deve permitir analisar os vários aspectos relacionados ao fenômeno em estudo.

Conforme discutido anteriormente, o presente artigo visa discutir acerca da Rede CSA Brasília, a qual está inserida na Rede CSA Brasil. Conforme o site da CSA Brasil, contabilizam-se cerca de 20 estados que possuem o modelo; nesses estados, têm-se 90 sedes que produzem e comercializam alimentos orgânicos, por meio da estrutura da CSA, organizadas em cerca de 110 pequenas unidades agrícolas no formato de redes comunitárias.

Para uma compreensão mais clara da área de pesquisa, está ilustrada na figura 1 a região que compreende o estado do Distrito Federal, o qual envolve a Capital Federal da República, Brasília, onde são apresentadas as 31 regiões administrativas. 
Figura 1 - Ilustração da região da Divisão Administrativa do Distrito Federal

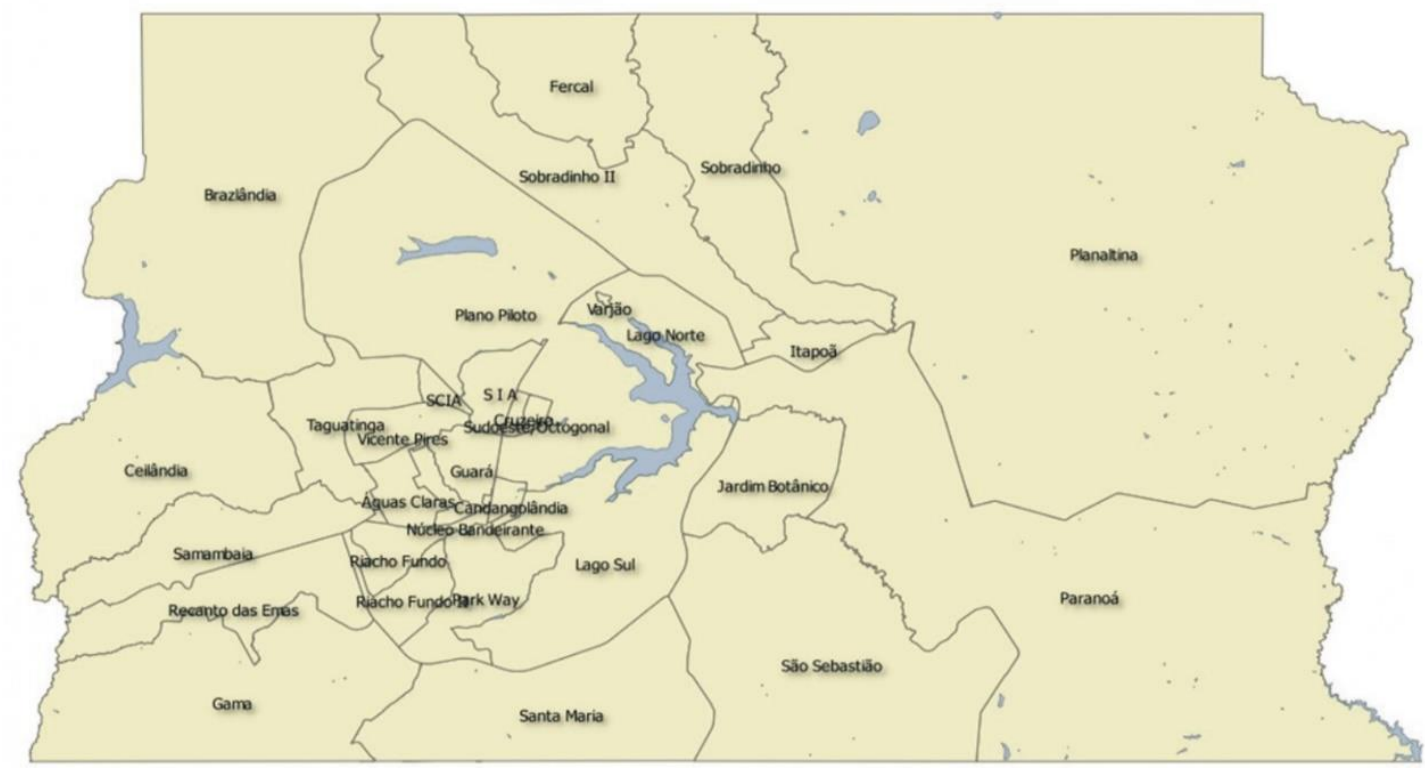

Fonte: Atlas do Distrito Federal 2017 (CODEPLAN, 2017).

$\mathrm{Na}$ figura 2, são apresentadas as regiões que abrangem o cinturão verde do Distrito Federal, o qual apresenta uma zona que abrange outro estado, Goiás, mas que comporta a grande parcela de produtores que abastecem o mercado orgânico do Distrito Federal, tornandose, também, alvo do estudo.

Figura 2 - Ilustração da periferia metropolitana do Distrito Federal

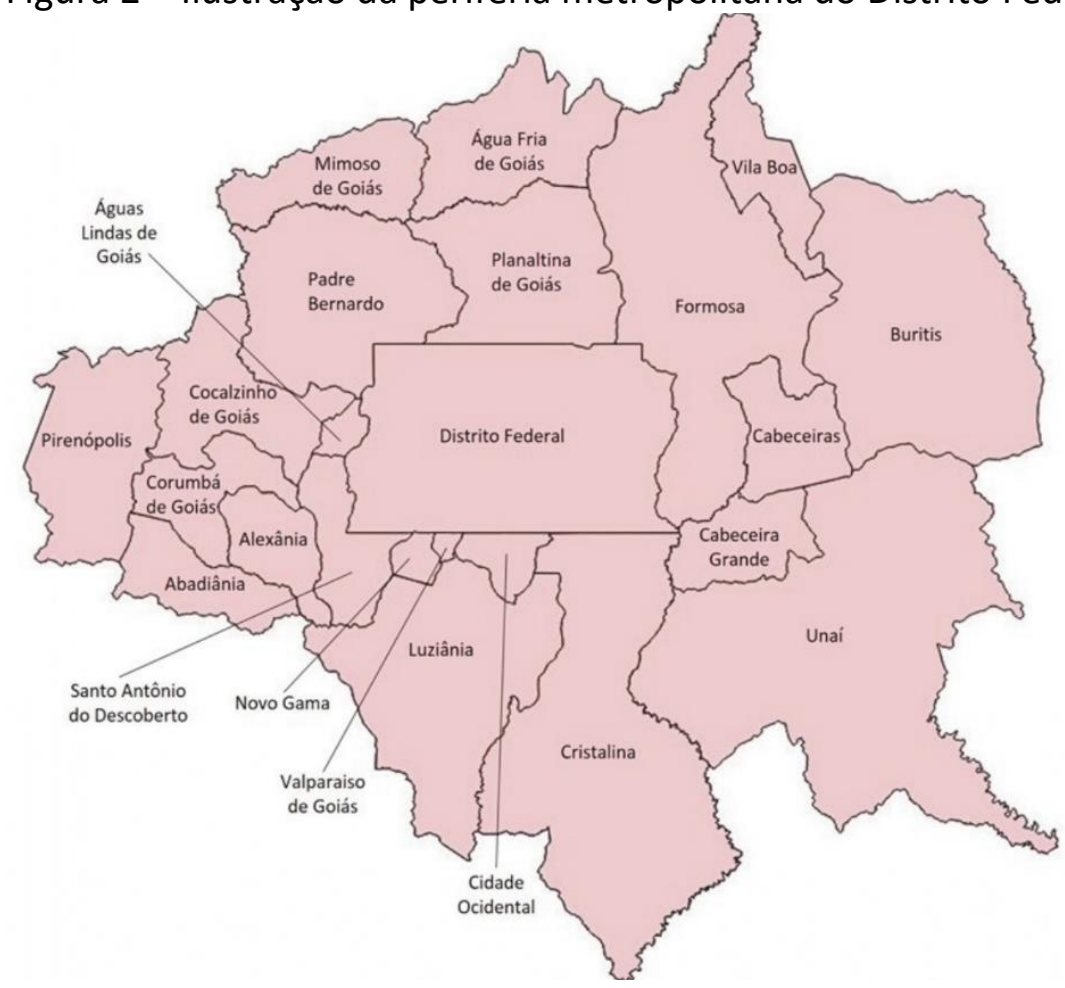

Fonte: Atlas do Distrito Federal 2017 (CODEPLAN, 2017).

Na figura 3, revela-se a distribuição das CSAs no Distrito Federal, evidenciando-se os 
pontos de conveniências, que estão representados por um marcador, e os pontos de produção, que estão marcados por uma representação de "planta".

Figura 3 - Figura ilustrativa das CSAs existentes atualmente no Distrito Federal

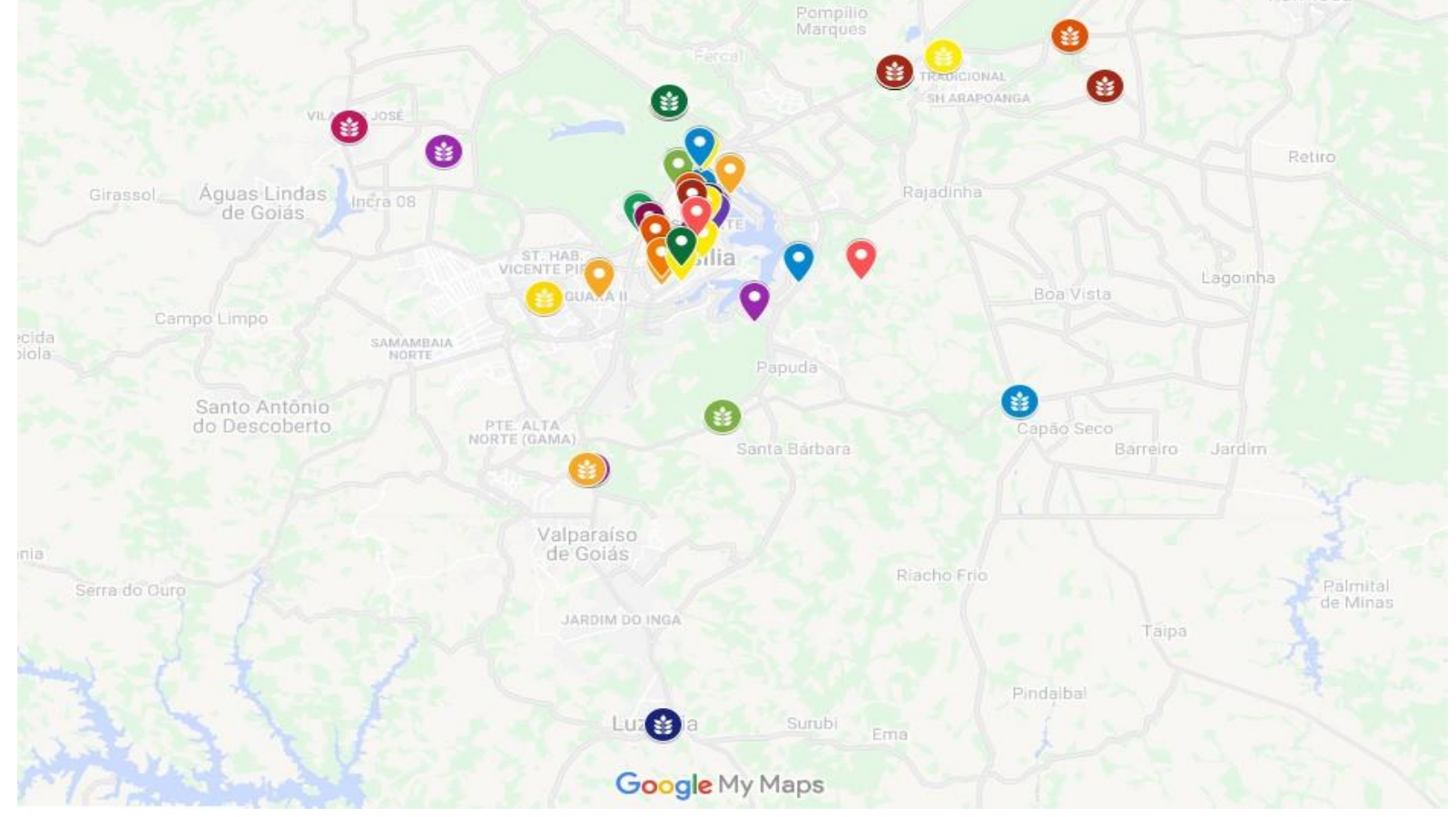

Fonte: CSA Brasília (2020).

Para a efetivação desta pesquisa, conduziram-se, por meio de revisão bibliográfica, buscas em diferentes bases científicas, nas seguintes plataformas: Google Acadêmico, Periódicos Capes, Scopus, Web of Science; também foram consultadas teses e dissertações utilizando os seguintes termos para busca: "comunidade que sustenta a agricultura" e "community supported agriculture", para alcançar uma referência tanto no âmbito nacional quanto no internacional, bem como ampliar a base de pesquisa, por ser um assunto de escala internacional, que acaba por possuir mais referências externas.

No âmbito dos trabalhos científicos desenvolvidos acerca do tema, identificou-se o trabalho intitulado "Exploring the synergy between Community Supported Agriculture and agroforestry: Institutional innovation from smallholders in a Brazilian rural settlement", dos autores Andrei Cechin, Victor da Silva Araújo e Louise Amand (2020). Nesse artigo, publicado no Journal of Rural Studies, os autores abordam uma unidade produtiva localizada no estado do Distrito Federal. Por isso, realizou-se contato via e-mail para marcar uma reunião via Google Meet, no final do mês de novembro de 2020, com Andrei Cechin, atualmente professor na Universidade de Brasília (UnB), para saber mais acerca da temática dentro do escopo do Distrito Federal. Em seguida, iniciou-se uma pesquisa para busca de dados para a fundamentação 
descritiva da pesquisa, por meio da home-page da organização das CSAs, nos âmbitos nacional (Brasil) e regional (Brasília), de modo a esclarecer dúvidas pertinentes ao funcionamento, à missão e à consolidação dentro da área pesquisada.

Para a coleta de dados referentes à comunidade localizada no Distrito Federal, foi estabelecido um contato com integrantes da comunidade, no período de agosto a outubro do ano de 2021, e foi realizada uma análise aprofundada do site e das informações divulgadas, para que se ampliasse a compreensão da dimensão da CSA do Distrito Federal e sobre como, atualmente, funciona o sistema de distribuição. A partir disso, foram entrevistados alguns agricultores, para avaliar a sua compreensão do funcionamento da CSA. Buscou-se, então, entender a Rede CSA Brasília por intermédio das informações coletadas nos sites e das informações coletadas a partir de entrevistas, que apresentassem aspectos dessa estrutura e como esta se comporta, tentando evidenciar a ocorrência de um processo de transição agroalimentar e se essa rede é uma representação disso. A partir disso, na próxima seção serão discutidos os resultados que foram obtidos na coleta de dados da pesquisa.

\section{Resultados e discussão}

\subsection{Comunidade que sustenta a agricultura}

As comunidades que sustentam a agricultura (CSAs) surgiram como uma rede alimentar com trabalho desenvolvido no formato de comunidade, que preza o bem-estar de uma alimentação mais equilibrada associada a um consumo consciente, avaliando não apenas as questões da saúde, como também as questões ambientais e econômicas envolvidas em um sistema produtivo. As CSAs foram efetivamente introduzidas no Brasil em 2011, na Fazenda Demétria, na cidade paulista de Botucatu. A repercussão desse modelo foi considerada um potencial de futuro pelo Fórum Social Mundial que ocorreu na cidade de Porto Alegre, RS, no mesmo ano. Do ponto de vista do interesse histórico, registra-se, com base em estudos do agrônomo Richard Charity, inspirado pelo modelo de CSA da Inglaterra, que a primeira implantação de uma CSA brasileira ocorreu na cidade de Fortaleza, CE, pela Associação para o Desenvolvimento da Agropecuária Orgânica (ADAO), em 1997 (JUNQUEIRA; MORETTI, 2018).

Há certa incoerência nessas informações, visto que Preiss (2017) descreve duas outras primeiras iniciativas no país que datam de 1978, com a ex-Cooperativa Ecológica - Coolmeia, em Porto Alegre, e a Cooperativa de Consumidores Naturais do Rio - Coonatura, no Rio de Janeiro. 
Ao que parece, essas "primeiras" CSAs surgiram anos antes de o modelo CSA chegar ao Brasil, mas já apresentavam estruturas similares ao modelo que seria inserido posteriormente. No caso da ex-Cooperativa Ecológica Coolmeia de Porto Alegre, esta não chegou a evoluir para um modelo de CSA como está sendo proposto atualmente.

A consolidação da Rede de CSA na região do Distrito Federal ocorreu por conta de três moradoras de Brasília, Fabiana Peneireiro, Renata Navega e Andrea Zimmermann, que já possuíam um cultivo na região do Distrito Federal, quando decidiram participar do Curso de Implantação de CSA Módulo Filosófico e Módulo Prático, que é ofertado pela CSA Brasil com intuito de capacitar novos afiliados. Conforme a CSA Brasília (2020), elas foram responsáveis por trazer o movimento CSA para o Distrito Federal, no ano de 2012. Dessa forma, começaram a se desenvolver ensaios iniciais com esse grupo na Chácara Toca da Coruja, onde foram feitos os primeiros plantios e encontros para diálogos sobre como poderia ser implantada uma CSA em Brasília.

A implantação da CSA de Brasília levou em conta os princípios mais gerais de uma CSA, quais sejam: a produção orgânica, local e ausente de intermediários. Também foram considerados outros aspectos, tais como: valorização da agricultura familiar; fortalecimento da agroecologia; gerenciamento participativo, democrático e rotativo; cultivo de interações harmônicas; postura de corresponsabilidade; promoção do contato dos coagricultores com a terra; incentivo da prática da economia associativa. Esses princípios trazidos para o Brasil são baseados no movimento comumente conhecido como Teikei, que está descrito no quadro 1 e é norteador do movimento das redes alimentares que datam de 1971, originado no Japão e representado pela Associação da Agricultura Orgânica do Japão (Japan Organic Agriculture Association - JOAA).

$\mathrm{Na}$ figura 4, observa-se que o consumidor tem a permissibilidade de participar da cadeia produtiva em níveis operacionais básicos de cada atividade, ou por meio da contribuição da mão de obra voluntária, com a organização das comissões, que têm o objetivo de auxiliar o agricultor a gerir a unidade produtiva. Exemplo dessas comissões implementadas são: comissão financeira e comissão de comunicação; estas são as mais comuns dentro das CSAs.

Já o produtor se mostra mais presente no processo pós-colheita, sendo o responsável pela confecção das cestas, pela distribuição nos pontos de conveniência e pela troca de informações pertinentes à produção. Dessa forma, há um estímulo a uma criação de laços com o consumidor, e, no caso da dieta, o produtor pode apenas sugerir produtos a serem utilizados, conforme a especificidade dos alimentos. 
Quadro 1 - Dez princípios de Teikei propostos pela JOAA

\begin{tabular}{|c|c|}
\hline Princípio & Significado \\
\hline Princípio da assistência mútua & $\begin{array}{l}\text { A essência desta parceria reside não no comércio em si, mas na relação } \\
\text { amigável entre as pessoas. Portanto, produtores e consumidores } \\
\text { devem ajudar-se mutuamente com base no entendimento mútuo: essa } \\
\text { relação deve ser estabelecida por meio da reflexão de experiências } \\
\text { passadas. }\end{array}$ \\
\hline Princípio da produção pretendida & $\begin{array}{l}\text { Os produtores devem, por meio de consulta aos consumidores, ter a } \\
\text { intenção de produzir a quantidade máxima e a variedade máxima de } \\
\text { produtos dentro da capacidade das fazendas. }\end{array}$ \\
\hline Princípio de aceitação do produto & $\begin{array}{l}\text { Os consumidores devem aceitar todos os produtos cultivados de } \\
\text { acordo com consulta prévia entre os dois grupos, e sua alimentação } \\
\text { deve depender tanto quanto possível desses produtos. }\end{array}$ \\
\hline $\begin{array}{l}\text { Princípio da concessão mútua na } \\
\text { decisão de preço }\end{array}$ & $\begin{array}{l}\text { Ao decidir o preço do produto, os produtores devem levar em conta a } \\
\text { economia de mão de obra e custo, devido à redução dos processos de } \\
\text { classificação e embalagem, bem como a aceitação de todos os seus } \\
\text { produtos; e os consumidores devem levar em conta o benefício de } \\
\text { obter alimentos frescos, seguros e saborosos. }\end{array}$ \\
\hline $\begin{array}{l}\text { Princípio de aprofundar } \\
\text { relacionamentos amigáveis }\end{array}$ & $\begin{array}{l}\text { O desenvolvimento contínuo desta parceria exige o aprofundamento } \\
\text { de relações de amizade entre produtores e consumidores. Isso será } \\
\text { alcançado apenas através da maximização do contato entre os } \\
\text { parceiros. }\end{array}$ \\
\hline Princípio da autodistribuição & $\begin{array}{l}\text { Por esse princípio, o transporte da produção deve ser feito pelos grupos } \\
\text { de produtores ou consumidores, até os depósitos destes últimos, sem } \\
\text { dependência de transportadores profissionais. }\end{array}$ \\
\hline incípio da gestão democrática & $\begin{array}{l}\text { Ambos os grupos devem evitar a dependência excessiva de um número } \\
\text { limitado de líderes em suas atividades e tentar praticar a gestão } \\
\text { democrática com responsabilidade compartilhada por todos. As } \\
\text { condições particulares das famílias dos membros devem ser levadas em } \\
\text { consideração com base no princípio da assistência mútua. }\end{array}$ \\
\hline $\begin{array}{l}\text { Princípio de aprendizagem entre } \\
\text { cada grupo }\end{array}$ & $\begin{array}{l}\text { Ambos os grupos de produtores e consumidores devem dar muita } \\
\text { importância ao estudo entre si e devem tentar evitar que suas } \\
\text { atividades acabem apenas na distribuição de alimentos seguros. }\end{array}$ \\
\hline $\begin{array}{l}\text { Princípio de manutenção da escala } \\
\text { de grupo apropriada }\end{array}$ & $\begin{array}{l}\text { A prática plena das questões citadas será difícil se o número de } \\
\text { membros ou o território desses grupos se tornar muito grande. Essa é } \\
\text { a razão pela qual ambos devem ser mantidos em um tamanho } \\
\text { adequado. O desenvolvimento deste movimento em termos de } \\
\text { membros deve ser promovido através do aumento do número de } \\
\text { grupos e da colaboração entre eles. }\end{array}$ \\
\hline Princípio de desenvolvimento estável & $\begin{array}{l}\text { Na maioria dos casos, nem os produtores nem os consumidores } \\
\text { poderão desfrutar das boas condições, deve-se fazer um esforço para } \\
\text { melhorar e avançar com colaboração mútua. }\end{array}$ \\
\hline
\end{tabular}

Fonte: adaptado do site da JOAA (2021).

Observa-se, a partir desse esquema, uma rede alternativa de produzir alimentos em um circuito curto de comercialização, proporcionando ao pequeno produtor o desenvolvimento de um sistema alimentar mais sustentável, economicamente viável, considerando o valor agregado socialmente, buscando pelo perfil desse consumidor mais ativo, que está interessado em consumir produtos que são cultivados de forma orgânica. Em contrapartida, o consumidor, que busca esse contato direto e próximo com os agricultores da região, promove o saber da origem do alimento, o que minimiza o custo de monitoramento desses produtos, já que o coagricultor 
consegue saber aspectos específicos do alimento, como: o não uso de agrotóxico, a maneira como o alimento foi produzido, o que resulta em uma alimentação mais rica nutricionalmente, na segurança alimentar e, consequentemente, na preservação do meio ambiente ao longo dos processos de plantio.

Figura 4 - Esquema da estrutura do modelo de coparceria entre consumidor e produtor do movimento Teikei da JOAA

$\begin{array}{lll}\text { Areas de } & \text { Atividades } & \\ \text { Atividade } & \text { Diárias } & \text { Ideias Principais }\end{array}$

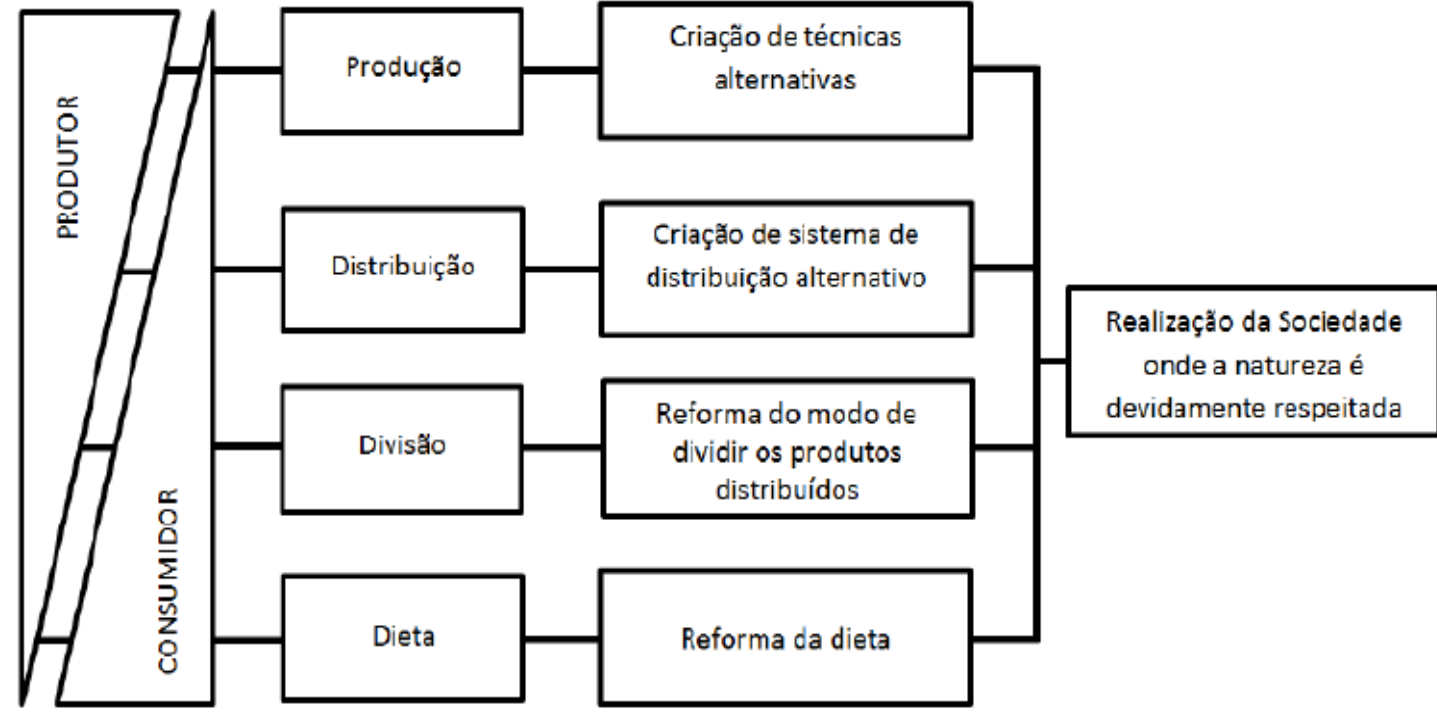

De "Agricultura Orgânica no Japão" por Shigeru Yasuda

Fonte: adaptado do site da JOAA (2021).

O produtor, além de conseguir mensurar sua demanda e os pontos de escoamento da produção, também evita possíveis perdas de qualidade e manuseios desnecessários. Esse contato acaba por gerar laços sociais entre os agentes envolvidos, que criam uma conexão pessoal, além da comercialização dos produtos (HINRICHS, 2000; BOUGHERARA; GROLLEAU; MZOUGHI, 2009). Dessa forma, esse sistema permite manter a disponibilidade de alimentos a um preço conveniente e faz com que sua produção, sua distribuição e sua venda sejam realizadas com o menor risco para todos os participantes.

Logo, conforme apresentado na Figura 5, apresenta-se o esquema do sistema de distribuição, que prega a parceria entre agricultores e coagricultores como um meio benéfico de entregar, diretamente aos clientes regionais, produtos frescos e de alta qualidade, que são cultivados localmente (WOODS; ERNST; TROPP, 2017; JUNQUEIRA; MORETTI, 2018). Desse modo, tem-se a estrutura do modelo de coparceria entre o consumidor e o produtor do movimento, apresentada na Figura 4, em conjunto com o esquema de distribuição apresentado 
na Figura 5, que, juntos, formam o ideal das redes comunitárias alimentares, que buscam seguir, de forma geral, os princípios contidos no Quadro 1, no sentido de promover uma estrutura de governança.

Figura 5 - Esquema de distribuição de coparceria entre consumidor e produtor do movimento Teikei

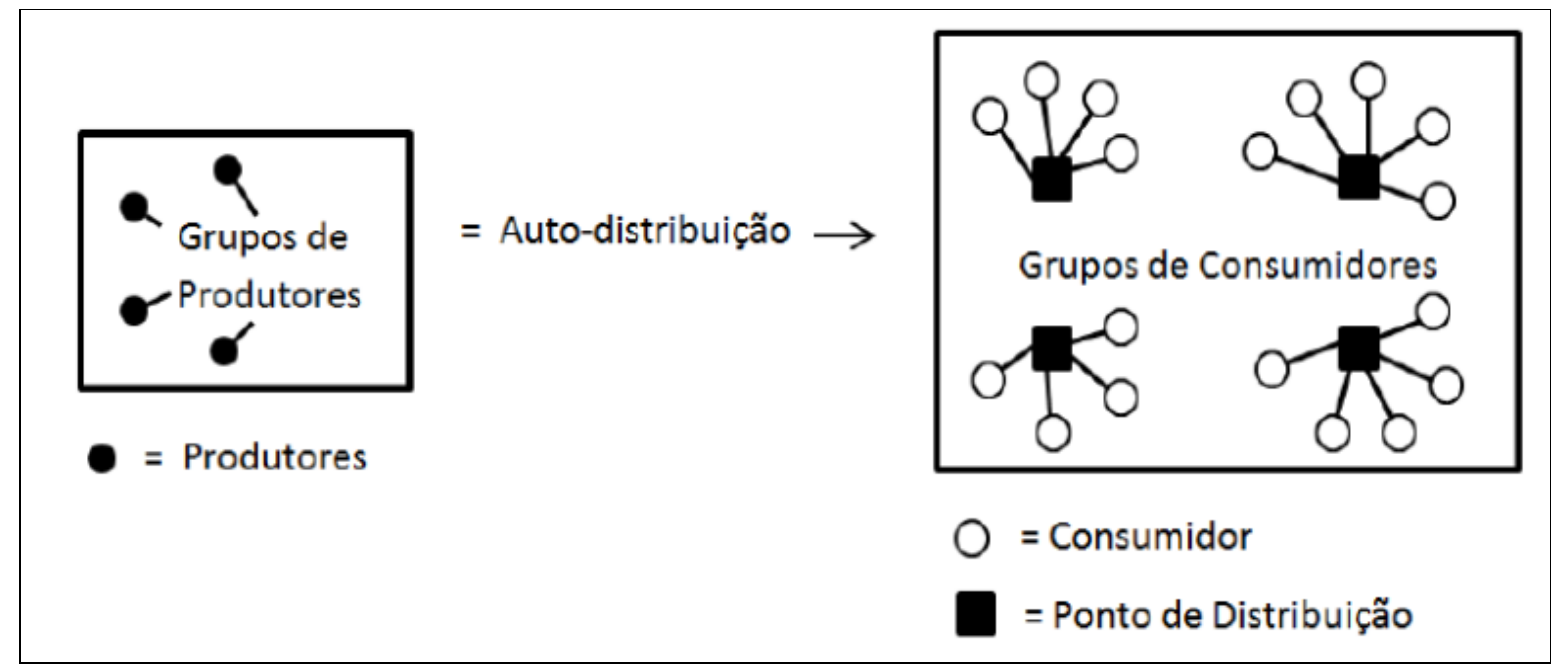

Fonte: adaptado do site da JOAA (2021).

Essa mesma estrutura, seguindo esses princípios, está composta numa rede internacional de CSAs, URGENCI, que descreve o modelo como Local solidarity partnerships between producers and consumers (LSPPC), que em português significa "uma parceria local e solidária entre produtores e consumidores". Com essa definição de modelos LSPPC feita pela URGENCI, pretende-se agregar inúmeras comunidades espalhadas pelo mundo e com diferentes denominações: "CSA" (Estados Unidos, Reino Unido, Austrália, Brasil, Bulgária); "AMAP" (França); “ASC" (Canadá); “ASAT” (Romênia); "FRACP” (Suíça); “GASAP” (Bélgica); "GAS” (Itália); "GSR" (Croácia); “SoLaWi” (Alemanha); “Socio-Ecological Agriculture” (China); "Teikei” (Japão); “Huellas Verdes” (Chile); “Granja Valle Pintado” (Argentina); “Canastas Comunitárias” (Equador); "Reciproco" (Portugal); entre outras.

As CSAs vêm promovendo não só a produção de alimentos orgânicos e mais saudáveis, como também a integração e a interação entre todos os atores envolvidos, além de profundas transformação e reeducação sobre consumo, economia e escoamento da produção. Assim, assumem-se outras variáveis na hora de tomar a decisão em relação à compra de produtos, não sendo baseada exclusivamente no "preço", mas também na agregação de valores baseados no "apreço".

Outro ponto, levando em conta a alimentação, é que essa não se restringe apenas a uma satisfação de uma necessidade biológica. Pelo lado do sistema econômico, a alimentação é um COLÓQUIO - Revista do Desenvolvimento Regional - Faccat - Taquara/RS - v. 19, n. 1, jan./mar. 2022 180 
fator estratégico, um elemento altamente relacional e influenciável pelas relações sociais daqueles que a manipulam, produzem e consomem. Podemos ver isso na consolidação e no desenvolvimento da CSA no Distrito Federal, com a implementação de cursos de capacitação na região e a interação com universidades e órgãos que divulgam o plantio sustentável, havendo uma rápida disseminação de locais produtivos aos que se filiaram. Em contrapartida, existe também a promoção de mais pontos de conveniências em pontos estratégicos, para que o coagricultor possa manter a interação com os agricultores.

Desse modo, tem-se a configuração da rede no Distrito Federal com a CSA Brasília, com um total de 35 unidades agrícolas espalhadas pelo estado e seu entorno. Seguindo a ordem cronológica, apresentada na Figura 6, de acordo com a CSA Brasília (2020): em agosto de 2015, houve a formação da CSA Aldeia do Altiplano; em setembro de 2015, a criação do ponto de convivência do CSA Barbetta na FEPECS; em fevereiro de 2016, a formação da CSA Batata Doce; em março de 2016, a formação da CSA Girassol e da CSA Cultivida; em maio de 2016, a formação da CSA da Florestta; em junho de 2016, a formação da CSA Jardim de Gaia, que é a primeira CSA com produção biodinâmica em Brasília; em setembro de 2016, a formação da CSA Bindu; em outubro de 2016, a formação da CSA Doce Vida - APROSPERA (Associação de Produtores Agroecológicos do Alto São Bartolomeu); e, por fim, em novembro de 2016, a formação da CSA Esperança, da CSA Brotos D’Água e da CSA Bela Vista, Madre Terra e Sonho de Deus.

Com um levantamento mais detalhado para avaliar como funciona atualmente a distribuição de alimentos pelas regiões administrativas do Distrito Federal, foi constatado que, dentre as 31 regiões administrativas, atualmente, os pontos de conveniência atendem o total de 14, onde estão as seguintes regiões: Asa Norte (16), Asa Sul (11), Zona Central (7) e Setor Policial (1) pertencem à mesma região administrativa. As outras regiões que os pontos de conveniência atendem são: Águas Claras (2), Altiplano Leste (1), Gama (1), Grande Colorado (1), Guará II (1), Lago Norte (3), Lago Sul (1), Paranoá (1), Planaltina (1), São Sebastião (1), Sobradinho (1), Sudoeste (3) e Tororó (1). Os pontos de conveniência comercializam seus produtos, tendo atualmente um total de 53, com a finalidade de se aproximar da localização da residência dos coagricultores (consumidores).

Em uma região administrativa, ocorre, por vezes, de se ter a oferta de mais de um ponto de conveniência, o que facilita o escoamento das cotas de cada CSA. Para que ocorra uma distribuição ordenada, são estabelecidos um dia e um horário específicos em todos os pontos de conveniências para que os coagricultores realizem a coleta das cestas. Para que se possa ter esse planejamento de entrega, anteriormente, é trabalhado na CSA um planejamento de plantios e 
colheitas, com um calendário dos ciclos, que serve para especificar quais alimentos serão colhidos e com o encaixe para que esses alimentos sejam fornecidos em quantidade adequada com o número de cotas que aquela CSA atende. Dessa forma, há um planejamento com alimentos com ciclo médio de 14 semanas, além de se manter um controle, ocorrendo um registro da quantidade colhida semanalmente. A própria organização da CSA Brasília disponibiliza um caderno da matriz de ciclo de cultivo, com especificações de ciclo e duração da colheita de mais de 49 produtos.

Figura 6 - Cronologia da formação das CSAs no Distrito Federal

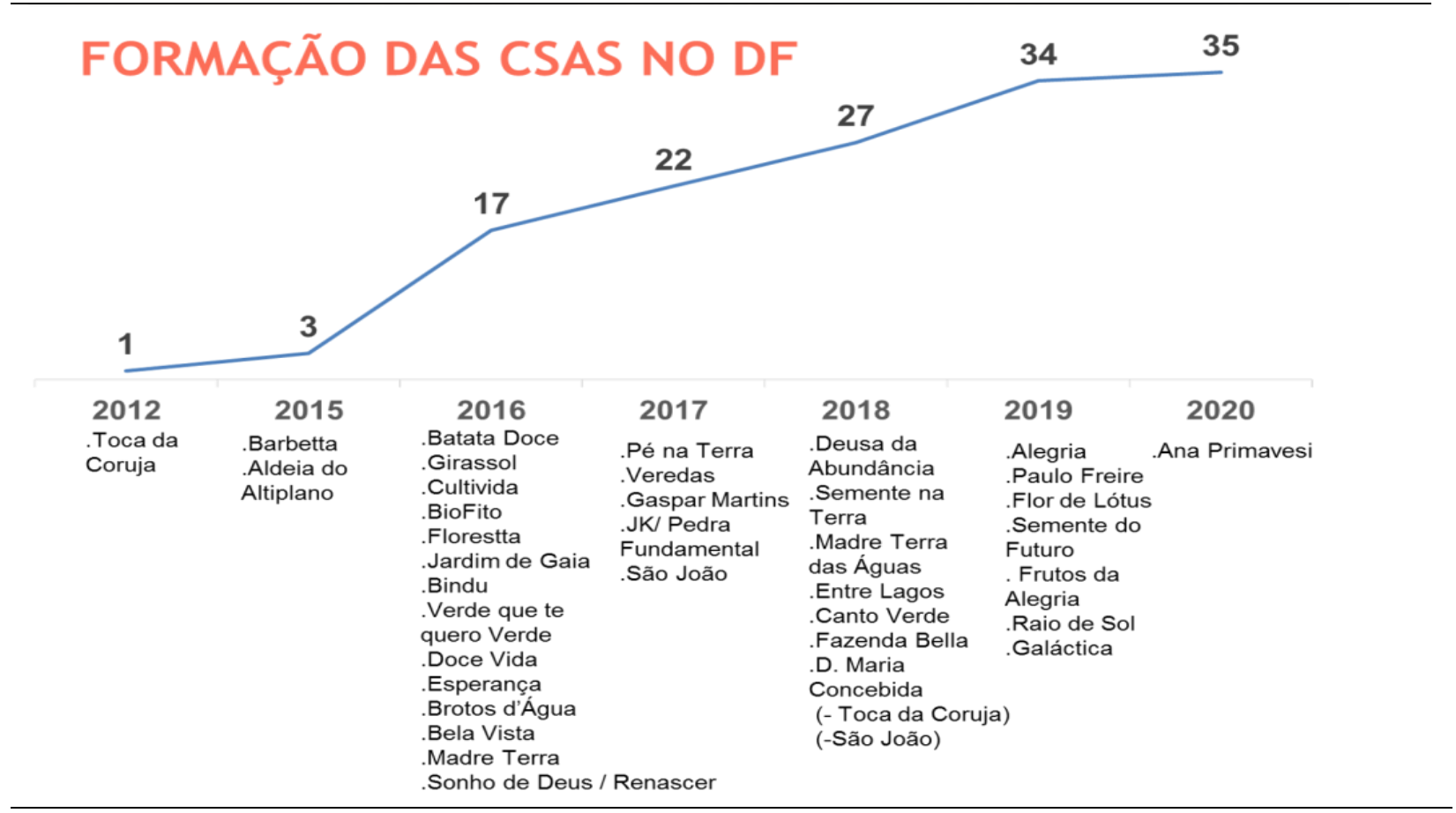

Fonte: CSA Brasília (2020).

Em relação aos alimentos a serem cultivados, esses são basicamente definidos pelos próprios agricultores, mas, mesmo havendo a centralização na figura do agricultor quanto à determinação de escolha de alimentos cultivados, busca-se flexibilidade, considerando a opinião dos coagricultores, por meio da consulta nos grupos de WhatsApp existentes. Além do entendimento geral de que o alimento que vem na cesta para aquela semana é o que está sendo produzido, respeitando a sazonalidade, pode ocorrer uma variação inesperada de itens em algumas cotas, devido à marcante sazonalidade de uma gama de alimentos, os quais geralmente sofrem grande influência do clima e da disponibilidade de água para seu cultivo.

Com um enfoque no coagricultor, esse tem a opção de duas categorias de cotas/cestas, que se restringe aos tamanhos $\mathrm{P}$ (pequeno) ou $\mathrm{M}$ (médio), mas em algumas CSAs ocorrem especificações diferentes. De toda forma, essa distribuição ocorre pelo número de opções de 
alimentos que conterá na cota disponibilizada na semana. Para que se tenha a questão da confiabilidade estendida ao coagricultor, a CSA compartilha, de forma transparente, o custo financeiro daquela produção e embute o valor médio da renda para o sustento daquela família que trabalha naquela propriedade, além de identificar o valor recolhido no fundo monetário para fins de prevenção contra eventualidades no sistema produtivo; caso ocorra algum imprevisto, pode-se recorrer àquele fundo.

Assim sendo, após esse entendimento, ocorre o fechamento de uma cota, que poderá ter a periodicidade de seis meses a um ano, em que o coagricultor assume o financiamento mensal de um valor referente à escolha de sua cota e, semanalmente, em um dia estabelecido, busca sua cesta. No dia anterior, o agricultor, por meio do grupo do WhatsApp, informa o que foi colhido e o que conterá na cesta, alguns coagricultores optam por adicionar alguns itens suplementares, como ovos, mel, cogumelos, entre outros produtos. Esses produtos adicionados também respeitam a sazonalidade e geram uma interação entre as CSAs e outras propriedades, para que se possa ter a troca de alimentos mais específicos, promovendo a variedade de produtos e a integração de toda a comunidade. A próxima subseção deste artigo tratará da questão da transição do sistema agroalimentar, relacionando, nesse contexto, as CSAs.

\subsection{Transição do sistema agroalimentar}

A partir do entendimento da Rede CSA, busca-se atrelar esse movimento com a compreensão da transição do regime agroalimentar. Assim, propõe-se analisar se esse modelo decorre de uma tendência da mudança da demanda dos mercados. Nesse sentido, analisam-se as mudanças de hábitos de forma gradativa, em que se tem o consumidor com mais consciência acerca dos danos que vêm sendo causados à saúde, como a síndrome metabólica, que compreende alterações nos níveis de glicemia, triglicérides, HDL-C e pressão arterial, levando ao desenvolvimento de doenças cardiovasculares, diabetes tipo 2 e obesidade, que são ocorrências diretas da má alimentação, pelo consumo excessivo de alimentos industrializados (PINTO et al., 2016). Tais aspectos também têm impulsionado a busca por maneiras alternativas de lidar com a agricultura, preocupando-se e optando tanto pela produção como pelo consumo de alimentos mais saudáveis. Um conjunto das respostas dessas procuras crescentes por formas de consumo mais conscientes é apresentado no quadro 2.

Conforme Pascucci (2010) desde o início dos anos 1990, muitas iniciativas surgiram, lideradas por movimentos sociais e representando grupos de produtores e consumidores ou por 
instituições locais, com o objetivo de reapropriar alimentos em nível local. Nesse caso, a CSA se configura como um modelo de escala local, principalmente urbano, o que reforça a agricultura periurbana, em que o objetivo é aproximar o consumidor e o campo, com consumidores mais ativos que também buscam imergir dentro dos princípios levantados pela CSA. Logo, esse consumidor se torna o stakeholder da produção, já que financia a produção e, além disso, é o único dentro da cadeia de distribuição, não tendo intermediários no processo.

Ao se observar os outros exemplos de redes comunitárias espalhadas pelo mundo, temse a concepção da agricultura alternativa, na qual cada rede busca focar em uma falha presente no mercado agroalimentar, como o desperdício, buscando o consumo de alimentos de uma forma mais sustentável e criando uma comunidade que se ajuste ao modelo desenvolvido. Esse modelo pode ser de escala global ou local, no caso da CSA, trata-se de um movimento de escala internacional, porém a atuação ocorre localmente, como também é o caso de grande parte dos outros modelos que possuem uma dimensão global da parte estratégica e gerencial do modelo, mas a atuação produtiva ocorre de forma local, ou seja, nas unidades produtivas vinculadas à região de sua abrangência.

Quadro 2-Exemplos de redes comunitárias de alimentos

\begin{tabular}{|c|c|c|c|c|c|}
\hline \multicolumn{2}{|c|}{ Tipo de comunidade } & Escala de ação & Objetivos & $\begin{array}{l}\text { Stakeholders } \\
\text { envolvidos }\end{array}$ & $\begin{array}{l}\text { Principais } \\
\text { recursos }\end{array}$ \\
\hline \multicolumn{2}{|c|}{$\begin{array}{l}\text { Agricultura apoiada pela } \\
\text { comunidade (CSA) }\end{array}$} & $\begin{array}{c}\text { Local (e } \\
\text { principalmente } \\
\text { urbano) }\end{array}$ & $\begin{array}{l}\text { Conectar consumidores às } \\
\text { produções alimentícias }\end{array}$ & $\begin{array}{c}\text { Consumidores } \\
\text { urbanos e } \\
\text { administradores } \\
\text { de terras }\end{array}$ & $\begin{array}{c}\text { Terra, } \\
\text { alimentação, } \\
\text { valores, tempo } \\
\text { livre (lazer) }\end{array}$ \\
\hline \multicolumn{2}{|c|}{$\begin{array}{l}\text { Grupos de compra de } \\
\text { consumidores (CBG) }\end{array}$} & Local & $\begin{array}{l}\text { Promover consumos críticos } \\
\text { e produções sustentáveis }\end{array}$ & $\begin{array}{c}\text { Consumidores e } \\
\text { agricultores } \\
\text { locais }\end{array}$ & \multirow{5}{*}{$\begin{array}{l}\text { Alimentos e } \\
\text { valores }\end{array}$} \\
\hline \multicolumn{2}{|c|}{$\begin{array}{l}\text { Mercados dos } \\
\text { agricultores (FM) }\end{array}$} & Local & $\begin{array}{c}\text { Fornecer alternativas de } \\
\text { comercialização aos } \\
\text { agricultores }\end{array}$ & $\begin{array}{l}\text { Agricultores e } \\
\text { consumidores } \\
\text { locais }\end{array}$ & \\
\hline \multirow{3}{*}{$\begin{array}{c}\text { Comunidades } \\
\text { baseadas em } \\
\text { TIC }\end{array}$} & $\begin{array}{l}\text { Fair } \\
\text { trade }\end{array}$ & Global & $\begin{array}{c}\text { Promover a redução da } \\
\text { desigualdade no comércio } \\
\text { internacional de produtos } \\
\text { alimentícios }\end{array}$ & $\begin{array}{l}\text { Agricultores de } \\
\text { LDCs e } \\
\text { consumidores } \\
\text { em DCs }\end{array}$ & \\
\hline & $\begin{array}{l}\text { Slow } \\
\text { food }\end{array}$ & Global & \multirow{2}{*}{$\begin{array}{c}\text { Promover o } \\
\text { desenvolvimento } \\
\text { sustentável, defesa das } \\
\text { tradições e das produções } \\
\text { locais }\end{array}$} & $\begin{array}{l}\text { Comunidades } \\
\text { locais e globais }\end{array}$ & \\
\hline & FAIREA & Local & & $\begin{array}{l}\text { Comunidades } \\
\text { locais }\end{array}$ & \\
\hline
\end{tabular}

Fonte: Pascucci (2010).

Segundo Pascucci (2010), a ideia é a existência de uma organização em torno do gerenciamento de produções locais numa escala global. Como exemplos, têm-se os casos dos 
movimentos Fair-Trade e da história de sucesso do Slow Food italiano, bem como a iniciativa mais recente do austríaco FAIREA. Estreitamente relacionadas à CSA, outras iniciativas locais de redes comunitárias alimentares estão surgindo, tais como Consumer Buying Groups (CBG) e Farmers' Markets (FM) ou Short-Chain (SC). A diferença entre os modelos se configura principalmente no mecanismo de tomada de decisões, sendo este, no caso da CSA, mais relacionado a padrões de consumo e padrões relacionados ao consumidor (PASCUCCI, 2010).

O mercado é altamente competitivo, principalmente o mercado agrícola, que possui muitos produtores e compradores/intermediários, em que cada um dos participantes tem impactos insignificativos sobre o preço de mercado. Já na perspectiva dos modelos discutidos anteriormente, leva-se em conta que a cadeia é de menor dimensão e faz com que os participantes envolvidos tenham um peso grande. Pois, como se pode observar no Quadro 2, na grande parte dos modelos, os stakeholders envolvidos, geralmente, são os produtores associados aos movimentos que formam a comunidade alimentar e aqueles consumidores que apoiam o movimento, logo, estes possuem grande impacto dentro dessas cadeias.

Dessa forma, analisando os aspectos centrais desses movimentos que ganham forma por volta dos anos 1990, observa-se que, naquele período, conforme apresentado no Quadro 3, no levantamento das principais características dos três regimes alimentares desenvolvido por Schneider, Schubert e Escher (2016), é mencionado o terceiro regime alimentar: "corporativoambiental", marcado ainda pelos Estados Unidos da América, que dominou o regime anterior e se mantém. Porém, na sequência, surgem outros países, como a China, com flexibilização da produção, facilidades na circulação dos alimentos a longas distâncias, preocupação com a qualidade dos alimentos, segurança alimentar, fome, padrões de controle sanitários, produtivos e de transportes, entre outros (SCHNEIDER; SCHUBERT; ESCHER, 2016).

Há também outros dois regimes. O primeiro regime, conhecido por "colonial-diaspórico", ocorreu entre 1870 e 1930, com a Grã-Bretanha como centro do poder, um regime que foi marcado pela redução dos custos dos alimentos para a população urbana, emigração em massa de camponeses da Europa para as novas colônias, surgindo assim a agricultura familiar e, por fim, a criação da classe de agricultores dependentes das exportações (SCHNEIDER; SCHUBERT; ESCHER, 2016). O segundo regime alimentar, ocorrido entre 1950 e 1970, conhecido por "mercantil-industrial", que teve como polo os Estados Unidos, foi um período de transição desenvolvimentista, que já buscava utilizar instrumentos mecânicos e químicos para a produção do alimento, que começava a ter um processamento visando à comodidade na hora do consumo. Outro ponto marcante nesse período foram os subsídios para alimentos americanos, que 
acabaram por desestimular a produção interna em diversos países.

Quadro 3 - Resumo dos três regimes alimentares: de 1870 aos dias atuais

\begin{tabular}{|c|c|c|c|}
\hline & $\begin{array}{l}\text { Primeiro regime } \\
\text { Alimentar }\end{array}$ & $\begin{array}{l}\text { Segundo regime } \\
\text { Alimentar }\end{array}$ & $\begin{array}{l}\text { Emergente, Terceiro } \\
\text { regime alimentar }\end{array}$ \\
\hline $\begin{array}{c}\text { Começo } \\
\text { aproximado }\end{array}$ & $1870-1930$ & $1950-1970$ & 2000-dias atuais \\
\hline Nome/definição & Colonial-Diaspórico & Mercantil-Industrial & Corporativo-Ambiental \\
\hline $\begin{array}{c}\text { País como } \\
\text { centro de poder }\end{array}$ & Grã-Bretanha & Estados Unidos & Eixo China/EUA \\
\hline $\begin{array}{l}\text { Principal } \\
\text { dirigente ou } \\
\text { tomador de } \\
\text { decisões }\end{array}$ & $\begin{array}{l}\text { Estados (principalmente } \\
\text { os colonizadores) } \\
\text { nacionais e fazendeiros }\end{array}$ & $\begin{array}{l}\text { Companhias } \\
\text { processadoras }\end{array}$ & $\begin{array}{c}\text { Corporacões } \\
\text { transnacionais do setor } \\
\text { varejistas, } \\
\text { supermercados }\end{array}$ \\
\hline $\begin{array}{l}\text { Modo de } \\
\text { regulação e } \\
\text { Governança }\end{array}$ & Impérios coloniais & $\begin{array}{l}\text { Estados Nacioanis via } \\
\text { Keynesianismo } \\
\text { gerenciado }\end{array}$ & Desregulação neoliberal \\
\hline $\begin{array}{c}\text { Ideologias } \\
\text { Dominantes }\end{array}$ & Liberalismo-Colonialismo & $\begin{array}{l}\text { Desenvolvimentismo- } \\
\text { AntiComunismo }\end{array}$ & $\begin{array}{l}\text { Neoliberalismo- } \\
\text { Globalização }\end{array}$ \\
\hline $\begin{array}{c}\text { Sistema } \\
\text { Monetário } \\
\text { Internacional }\end{array}$ & Padrão Ouro-Libra & $\begin{array}{c}\text { Ouro-Dólar (Bretton } \\
\text { Woods) }\end{array}$ & $\begin{array}{l}\text { Dólar-Flexível (Pós-B. } \\
\text { Woods) }\end{array}$ \\
\hline $\begin{array}{l}\text { Paradigma } \\
\text { Agro- } \\
\text { Tecnológico }\end{array}$ & Tradicional & Mecânica e Química & $\begin{array}{c}\text { Bio-e-nano-tecnologias, } \\
\text { TIC's }\end{array}$ \\
\hline $\begin{array}{l}\text { Características } \\
\text { dos alimentos }\end{array}$ & $\begin{array}{c}\text { Gêneros alimentícios } \\
\text { básicos para preparação } \\
\text { caseira }\end{array}$ & $\begin{array}{l}\text { Gêneros alimentícios } \\
\text { básicos e processados } \\
\text { para preparação caseira } \\
\text { e refeições fora de casa }\end{array}$ & $\begin{array}{c}\text { Gêneros alimentícios } \\
\text { básicos, processados e } \\
\text { manufaturados para } \\
\text { preparação caseira, } \\
\text { conveniência e } \\
\text { refeições flexibilizadas }\end{array}$ \\
\hline Identificador & $\begin{array}{l}\text { Produtos sem marca e } \\
\text { sem diferenciação }\end{array}$ & Produtos de marca & $\begin{array}{l}\text { Produtos de marca, } \\
\text { marcas dos próprios } \\
\text { supermercados e } \\
\text { marcas genéricas }\end{array}$ \\
\hline $\begin{array}{l}\text { Movimentos } \\
\text { Contestação }\end{array}$ & Trabalhadores & Agricultores & Consumidores \\
\hline
\end{tabular}

Fonte: Schneider, Schubert e Escher (2016, p. 36).

Tudo isso gerou movimentos e mudanças no cenário global. Um ponto importante é o processo de urbanização, que gerou um aumento na demanda por produtos agroalimentares altamente processados e de qualidade nas áreas urbanas, contribuindo com a expansão da classe média das áreas emergentes e o aumento da renda per capita, para aproximar as escolhas de consumo de grandes parcelas da população mundial dos estilos alimentares das regiões mais ricas do planeta (convergência de hábitos alimentares) (IFAD, 2016).

Segundo o Relatório de Desenvolvimento Rural (IFAD, 2016), espera-se que 68\% da população mundial viva em áreas urbanas até 2050 , em comparação com os atuais 55\%, com $70 \%$ de todos os alimentos já destinados ao consumo em áreas urbanas. Nesse sentido, as cidades estão se tornando pontos críticos para a sustentabilidade dos sistemas alimentares globais e os esforços para a mitigação e/ou adaptação às mudanças climáticas.

Observa-se que houve uma mudança entre os regimes que proporcionou o que hoje representa o sistema agroalimentar, o uso intensivo de tecnologias, a mudança das instituições 
tomadoras de decisões, além dos definidores da demanda de mercado. O mercado é uma variável constante que se adapta conforme a necessidade, sendo que a mudança atual é representada pela grande parcela da população residente nas áreas urbanas e tem-se uma comoção em encontrar um novo equilíbrio para o sistema produtivo que consiga suprir o mercado global.

Dessa forma, no quadro 4, pode-se observar que a transição do regime agroalimentar ocorre de forma regular, com o surgimento de alguns movimentos que buscam minimizar os impactos ambientais, até mesmo com a grande indústria tendo que se adaptar aos protocolos internacionais, com condicionalidades para a venda de mercadoria no comércio exterior, em contrapartida, para o monitoramento, há agências fiscalizadoras com um papel mais intenso.

Quadro 4-Perspectivas para um possível regime alimentar fundamentado nas percepções do estudo

\begin{tabular}{|l|l|l|}
\hline \multicolumn{3}{|c|}{ Regime misto } \\
\hline & Regime alimentar local & Regime alimentar internacional \\
\hline $\begin{array}{l}\text { Tomadores de } \\
\text { decisões }\end{array}$ & $\begin{array}{l}\text { Produtores, visando à opinião do } \\
\text { consumidor; produtor participante do } \\
\text { processo produtivo. }\end{array}$ & $\begin{array}{l}\text { Grandes corporações da cadeia de } \\
\text { commodities, seguindo protocolos ambientais } \\
\text { para conseguir atingir as condicionalidades da } \\
\text { venda. }\end{array}$ \\
\hline $\begin{array}{l}\text { Demanda } \\
\text { produtiva }\end{array}$ & $\begin{array}{l}\text { Busca por alimentos produzidos } \\
\text { localmente, que proporcionem interações } \\
\text { e agregação de valor. }\end{array}$ & Alta demanda por commodities. \\
\hline Agricultura & $\begin{array}{l}\text { Cadeia curta, redes comunitárias. } \\
\text { agroecologia, permacultura e agricultura } \\
\text { periurbana, localizados nos cinturões } \\
\text { verdes. }\end{array}$ & Incentivo da agricultura de larga escala. \\
\hline Região & $\begin{array}{l}\text { Perto dos centros urbanos. } \\
\text { Cadeia longa. }\end{array}$ \\
\hline
\end{tabular}

Fonte: elaboração dos autores.

Nesse contexto, com a população mais urbanizada, necessita-se de um mercado próximo para abastecer tal demanda, com consumidores mais ativos e preocupados além da sua dieta, buscando algo que ultrapasse a embalagem fechada na prateleira do mercado. Não é que não se busque mais a comodidade, todavia, também importam as interações sociais, em que se enxerga o alimento não apenas a partir das suas características fisiológicas, mas também simbólicas, relacionados à proteção ambiental e à valorização cultural.

Logo, percebe-se a interação desses dois regimes, um com foco local/regional, suprindo a demanda dos grandes centros urbanos com alimentos com características simbólicas; e outro com foco internacional, para o suprimento das cadeias longas, com processamento e 
industrialização do produto, como se vê atualmente, porém, seguindo maiores restrições na produção e no processamento da mercadoria. Isso pode gerar o uso de maiores aparatos tecnológicos no auxílio de manter a alta produtividade e, simultaneamente, ser sustentável.

\section{Considerações finais}

A partir da explanação realizada até o momento, explorando a concepção e a dinâmica da Rede CSA no Distrito Federal, observa-se um movimento peculiar em relação ao regime alimentar existente, no qual, apesar de ser de escala global, tem-se uma participação intensa do consumidor, como um parceiro no processo produtivo, além da dinâmica de comunidade estabelecida nos grandes centros urbanos, desenvolvendo a agricultura periurbana. Contudo, voltando-se aos regimes anteriores, com a busca do fortalecimento da agricultura familiar e uma agricultura mais "natural", com um plantio marcado pela sustentabilidade e o desenvolvimento de ideologias e conceitos morais atrelados à produção, não tem tanta importância o conceito de marca, mas, sim, a "face do produtor", no sentido de o consumidor conseguir visualizar a origem daquele produto que está chegando até a sua mesa.

O ponto principal não é que existe apenas o movimento da CSA com essas características. Verifica-se uma tendência forte do conceito de redes alimentares, as quais automaticamente se desenvolveram a partir de experiências diversas, mas com os objetivos comuns de minimizar os impactos ambientais e promover laços entre os agentes econômicos. Com isso, a CSA acaba por atingir pequenos nichos, mesmo sem peso econômico ou poder para produzir a transformação necessária do sistema agroalimentar, tem a possibilidade de disseminar e aumentar a influência sobre os outros atores para que adotem esse modelo (CECHIN; SILVA ARAÚJO; AMAND, 2020).

É possível afirmar que, por meio da CSA ou de outras redes comunitárias alimentares, proporciona-se a facilitação da adoção de sistemas produtivos ambientalmente mais sustentáveis, a geração de renda no campo, o alívio da pobreza rural entre os pequenos produtores, com o fornecimento de alimentos para os centros urbanos e melhorias importantes na agricultura periurbana (CECHIN; SILVA ARAÚJO; AMAND, 2020). Além da disseminação da filosofia implementada dentro da CSA, tem-se um modelo inovador de comercialização e que abarca uma gama de ensinamentos acerca do que é o alimento, bem como sobre a sua importância no dia a dia.

Em meio à pandemia da Covid-19, com as feiras de produtos agrícolas fechadas, teve-se uma demonstração de como o sistema de comercialização de circuito curto implementado pelas 
CSAs tem se mantido em meio aos impactos sofridos, sem apresentar interrupções da comercialização. Isso se deve ao fato de que os pontos de comercialização são de fácil acesso e envolvem apenas o próprio produtor e o coagricultor. A não interrupção da produção é uma característica que se observou na agricultura de larga escala, que não parou sua produção e seu escoamento, apenas se adaptou aos novos protocolos de segurança.

Nesse sentido, é necessária a concepção de um regime agroalimentar misto, que vise tanto o regional quanto o comércio exterior, pois a agricultura local não consegue suprir uma demanda nacional, porém, consegue criar movimentos de âmbito internacional que promovam o abastecimento local. Em contrapartida, evidencia-se o papel da agricultura internacional, que visa produzir matéria-prima para a indústria, abastecendo o mercado com alimentos processados em larga escala, seguindo protocolos internacionais com contexto ambiental.

Apesar de a CSA estar se mostrando um representativo do movimento das redes comunitárias alimentares, ainda é uma realidade elitista, é um produto de excelente qualidade com custos maiores na produção, logo, atinge poucos consumidores na sociedade. Portanto, grande parte da sociedade ainda necessita da oferta dos produtos processados com um baixo custo para o suprimento alimentar diário.

\section{Referências}

BORSELLINO, V.; SCHIMMENTI, E.; EL BILALI, H. Agri-food markets towards sustainable patterns. Sustainability, v. 12, n. 6, p. 2193, 2020.

BOUGHERARA, D.; GROLLEAU, G.; MZOUGHI, N. Buy local, pollute less: What drives households to join a community supported farm? Ecological Economics, v. 68, n. 5, p. 1488-1495, 2009.

CECHIN, A.; SILVA ARAÚJO, V. da; AMAND, L. Exploring the synergy between Community Supported Agriculture and agroforestry: Institutional innovation from smallholders in a Brazilian rural settlement. Journal of Rural Studies, v. 81, n. October 2020, p. 246-258, 2020.

COMPANHIA DE PLANEJAMENTO DO DISTRITO FEDERAL - CODEPLAN. Atlas do Distrito Federal 2017. Disponível em: http://www.codeplan.df.gov.br/wp-content/uploads/2018/05/Atlas-doDistrito-Federal-2017.pdf. Acesso em: 26 ago. 2020.

CSA BRASIL. Disponível em: http://www.csabrasil.org/csa/. Acesso em: 26 ago. 2020.

CSA BRASÍLIA. Disponível em: https://csabrasilia.wordpress.com/. Acesso em: 26 ago. 2020.

HINRICHS, C. C. Embeddedness and local food systems: notes on two types of direct agricultural market. Journal of Rural Studies, v. 16, n. 3, p. 295-303, 2000.

INTERNATIONAL FUND FOR AGRICULTURAL DEVELOPMENT - IFAD. Rural Development Report 2016: Fostering Inclusive Rural Transformation. Rome, Italy: IFAD, 2016. 
JAPAN ORGANIC AGRICULTURE ASSOCIATION - JOAA. What is organic agriculture? Disponível em:

https://www.1971joaa.org/\%E6\%9C\%AC\%E4\%BC\%9A\%E3\%81\%AB\%E3\%81\%A4\%E3\%81\%84\%E 3\%81\%A6/about-us/about-us-html/. Acesso em: 02 de abril de 2021.

JUNQUEIRA, A. H.; MORETTI, S. L. do A. Comunidade que Sustenta a Agricultura (CSA): tecnologia social de venda direta de alimentos e de revalorização das identidades alimentares territoriais. Estudos Sociedade e Agricultura, v. 26, n. 3, p. 517-538, out. 2018.

PASCUCCI, S. Governance Structure, Perception and Innovation in Credence Food Transactions: The Role of Community Networks. Proceedings in Food System Dynamics, v. 0, n. 0, p. 647-660, 2010.

PINTO, M. E. M. et al. Alimentação saudável: prevenindo a síndrome metabólica. Segurança Alimentar e Nutricional, v. 23, n. 2, p. 944-954, 2016.

PREISS, P. V. As alianças alimentares colaborativas em uma perspectiva internacional: afetos, conhecimento incorporado e ativismo político. Tese (Doutorado em Desenvolvimento Rural) Faculdade de Ciências Econômicas, Programa de Pós-Graduação em Desenvolvimento Rural, Universidade Federal do Rio Grande do Sul, Porto Alegre, 2017.

SCHNEIDER, S.; SCHUBERT, M. N.; ESCHER, F. Regimes agroalimentares e o lugar da agricultura familiar: uma apresentação ao debate. Revista Mundi Meio Ambiente e Agrárias, Curitiba, PR, v. 1, n. 1, p. 3.1-3.20, jan./jun. 2016.

SELLTIZ, C.; WRIGHTSMAN, L. S.; COOK, S. W. Métodos de pesquisa das relações sociais. São Paulo: Herder, 1965.

UNITED NATIONS. Transforming Our World: The 2030 Agenda for Sustainable Development; Resolution adopted by the General Assembly on 25 September 2015. New York, NY, USA: United Nations, 2015.

WOODS, T.; ERNST, M.; TROPP, D. Community supported agriculture: new models for changing markets. United States Department of Agriculture, Agricultural Marketing Service, 2017. 